\title{
Prognostic Value and Influence of Receptor Conversion on Treatment Regimen in Metastatic Breast Cancer at the First Time of Recurrence
}

\author{
Jiming Shen ${ }^{a, b}$ Lu Xu ${ }^{a, b}$ Jing Shi ${ }^{a, b}$ Lei Zhao ${ }^{a, b}$ Sha Shi, ${ }^{a, b}$ Jing Feng ${ }^{a, b}$ \\ Xu Han ${ }^{a, b}$ Yu Shi ${ }^{a, b}$ Qiaochu Wei ${ }^{a, b}$ Dongni Wang ${ }^{a, b}$ Mingfang Sun ${ }^{c}$ \\ Xiaoyi Mic Yue'e Teng ${ }^{\mathrm{a}}{ }^{\mathrm{a}} \mathrm{b}$ \\ a Department of Medical Oncology, First Hospital of China Medical University, Shenyang, China; ${ }^{\mathrm{b}}$ Key Laboratory \\ of Anticancer Drugs and Biotherapy of Liaoning Province, First Hospital of China Medical University, \\ Shenyang, China; ' Department of Pathology, First Hospital and College of Basic Medical Sciences of \\ China Medical University, Shenyang, China
}

\section{Keywords}

Estrogen receptor $\cdot$ Human epidermal growth factor receptor 2 - Progesterone receptor - Receptor conversion . Metastatic breast cancer tients with metastatic breast cancer should perform re-biopsy to clarify the receptor status of the first metastatic lesions, which may provide clinicians valuable evidence to conduct treatments with higher precision.

(c) 2020 S. Karger AG, Basel

\begin{abstract}
Purpose: At the first time of metastatic breast cancer recurrence, conversion of the receptors status may occur between primary lesions and metastatic lesions, including the estrogen receptor (ER), progesterone receptor (PR), and human epidermal growth factor receptor 2 (HER2). Whether the decision of the treatment regimen is based on the primary receptor status or that of metastatic lesions is still unclear. Methods: This study enrolled 411 female patients with a diagnosis of metastatic breast cancer at the first time of recurrence to explore the influence of receptor conversion on prognosis prediction and treatment regimen of patients with metastatic breast cancer. Results: ER and PR changes from negative to positive are both prognostic factors for patients with breast cancer. Patients receiving endocrine therapy showed a better survival after recurrence than those using chemotherapy alone in the ER or PR Prim- Met+ subgroup. Patients in the HER2 Prim- Met+ subgroup using HER2-targeted therapy in multilines showed a post-recurrence survival advantage. In the bone re-biopsy subgroup, the $P R$ change from positive to negative appeared to be more frequent than at other re-biopsy sites. Conclusions: $\mathrm{Pa}$ -
\end{abstract}

\section{Introduction}

Breast cancer has the highest incidence in women, and although survival has gradually improved over the years, one third of the patients diagnosed with early breast cancer will still progress to metastatic disease with a poor prognosis $[1,2]$. Therapy for breast cancer has been developed into precision treatments in which the status of the estrogen receptor (ER), progesterone receptor (PR), and human epidermal growth factor receptor 2 (HER2) is important [3-6]. Actually, a large part of treatment regimens for patients with metastatic breast cancer rely on hormone receptor status and the molecular subtype of the primary lesion. However, the correlation between the receptor conversion in metastatic lesions and the prognostic decision-making remains unclear.

Accumulating evidence has shown that the status of $\mathrm{ER}, \mathrm{PR}$, and HER2 is inconsistent to a certain extent between the primary and metastatic lesions, and the proportion of receptor conversion at different sites is not comparable [7-16]. In a previous clinical practice guideline, the 
Table 1. Patients' basic clinicopathological characteristics of their primary sites

\begin{tabular}{|c|c|c|c|c|c|c|c|c|c|c|}
\hline \multirow[t]{2}{*}{ Variable } & \multirow[t]{2}{*}{ All patients } & \multirow[t]{2}{*}{$\%$} & \multicolumn{4}{|l|}{ ER } & \multicolumn{4}{|l|}{ PR } \\
\hline & & & positive & $\%$ & negative & $\%$ & positive & $\%$ & negative & $\%$ \\
\hline Patients, $n$ & 411 & & 242 & 58.88 & 169 & 41.12 & 228 & 55.47 & 183 & 44.53 \\
\hline \multicolumn{11}{|l|}{ Biopsy of relapse } \\
\hline Puncture & 301 & 73.24 & & & & & & & & \\
\hline Surgery & 110 & 26.76 & & & & & & & & \\
\hline \multicolumn{11}{|l|}{ Age, years } \\
\hline Average & \multirow{2}{*}{\multicolumn{2}{|c|}{$48(26-79)$}} & \multirow{2}{*}{\multicolumn{2}{|c|}{$\begin{array}{l}47(26-79) \\
47(26-79)\end{array}$}} & \multirow{2}{*}{\multicolumn{2}{|c|}{$\begin{array}{l}47(26-76) \\
48(26-76)\end{array}$}} & \multirow{2}{*}{\multicolumn{2}{|c|}{$\begin{array}{l}46(26-79) \\
46(26-79)\end{array}$}} & \multicolumn{2}{|c|}{$50(28-76)$} \\
\hline Median & & & & & & & & & \multicolumn{2}{|c|}{$49(28-76)$} \\
\hline$<35$ years & 41 & 9.98 & 33 & 13.64 & 8 & 4.73 & 29 & 12.72 & 12 & 6.56 \\
\hline $35-60$ years & 331 & 80.54 & 185 & 76.45 & 146 & 86.39 & 181 & 79.39 & 150 & 81.97 \\
\hline$>60$ years & 39 & 9.49 & 24 & 9.92 & 15 & 8.88 & 18 & 7.89 & 21 & 11.48 \\
\hline \multicolumn{11}{|l|}{ Menopausal status } \\
\hline Menopause & 272 & 66.18 & 154 & 63.64 & 118 & 69.82 & 141 & 61.84 & 131 & 71.58 \\
\hline Premenopausal & 134 & 32.60 & 84 & 34.71 & 50 & 29.59 & 84 & 36.84 & 50 & 27.32 \\
\hline NA & 5 & 1.22 & 4 & 1.65 & 1 & 0.59 & 3 & 1.32 & 2 & 1.09 \\
\hline \multicolumn{11}{|l|}{ BMI, $n$} \\
\hline$\leq 18.4$ & 13 & 3.16 & 11 & 4.55 & 2 & 1.18 & 8 & 3.51 & 5 & 2.73 \\
\hline $18.5-23.9$ & 160 & 38.93 & 97 & 40.08 & 63 & 37.28 & 90 & 39.47 & 70 & 38.25 \\
\hline $24.0-27.9$ & 172 & 41.85 & 95 & 39.26 & 77 & 45.56 & 94 & 41.23 & 78 & 42.62 \\
\hline$\geq 28$ & 66 & 16.06 & 41 & 16.94 & 25 & 14.79 & 36 & 15.79 & 30 & 16.39 \\
\hline \multicolumn{11}{|l|}{ T stage, $n$} \\
\hline Tis & 8 & 1.95 & 3 & 1.24 & 5 & 2.96 & 3 & 1.32 & 5 & 2.73 \\
\hline $\mathrm{T} 1$ & 116 & 28.22 & 72 & 29.75 & 44 & 26.04 & 71 & 31.14 & 45 & 24.59 \\
\hline T2 & 227 & 55.23 & 133 & 54.96 & 94 & 55.62 & 123 & 53.95 & 104 & 56.83 \\
\hline T3 & 30 & 7.30 & 14 & 5.79 & 16 & 9.47 & 11 & 4.82 & 19 & 10.38 \\
\hline $\mathrm{T} 4$ & 12 & 2.92 & 6 & 2.48 & 6 & 3.55 & 6 & 2.63 & 6 & 3.28 \\
\hline NA & 18 & 4.38 & 14 & 5.79 & 4 & 2.37 & 14 & 6.14 & 4 & 2.19 \\
\hline \multicolumn{11}{|l|}{ N stage, $n$} \\
\hline N0 & 161 & 39.17 & 96 & 39.67 & 65 & 38.46 & 93 & 40.79 & 68 & 37.16 \\
\hline N1 & 110 & 26.76 & 63 & 26.03 & 47 & 27.81 & 57 & 25.00 & 53 & 28.96 \\
\hline N2 & 65 & 15.82 & 40 & 16.53 & 25 & 14.79 & 36 & 15.79 & 29 & 15.85 \\
\hline N3 & 54 & 13.14 & 27 & 11.16 & 27 & 15.98 & 25 & 10.96 & 29 & 15.85 \\
\hline NA & 21 & 5.11 & 16 & 6.61 & 5 & 2.96 & 17 & 7.46 & 4 & 2.19 \\
\hline Stage, $n$ & & & & & & & & & & \\
\hline 0 & 7 & 1.70 & 2 & 0.83 & 5 & 2.96 & 2 & 0.88 & 5 & 2.73 \\
\hline I & 65 & 15.82 & 41 & 16.94 & 24 & 14.20 & 37 & 16.23 & 28 & 15.30 \\
\hline II & 194 & 47.20 & 117 & 48.35 & 77 & 45.56 & 111 & 48.68 & 83 & 45.36 \\
\hline III & 120 & 29.20 & 64 & 26.45 & 56 & 33.14 & 59 & 25.88 & 61 & 33.33 \\
\hline NA & 25 & 6.08 & 18 & 7.44 & 7 & 4.14 & 19 & 8.33 & 6 & 3.28 \\
\hline HER2 status, $n$ & & & & & & & & & & \\
\hline HER2+ & 96 & 23.36 & 40 & 16.53 & 56 & 33.14 & 40 & 17.54 & 56 & 30.60 \\
\hline IHC only $^{1}$ & 30 & 7.30 & 18 & 7.44 & 12 & 7.10 & 18 & 7.89 & 12 & 6.56 \\
\hline HER2- & 270 & 65.69 & 175 & 72.31 & 95 & 56.21 & 162 & 71.05 & 108 & 59.02 \\
\hline NA & 15 & 3.65 & 9 & 3.72 & 6 & 3.55 & 8 & 3.51 & 7 & 3.83 \\
\hline
\end{tabular}

Median follow-up of the patients after relapse was 57.2 months. $n$, number of patients; NA, not available. ${ }^{1}$ HER2(++), FISH was not performed.

importance of reevaluating the receptor status in metastatic breast cancer lesions has been emphasized as the receptor conversion can provide important guidance for treatment and, consequently, improved prognosis [17]. Therefore, determination of the ER, PR, and HER2 status in metastatic lesions is key to treatment since hormone receptor status can affect treatment decisions to pave the way towards a better prognosis in metastatic breast cancer. Therapeutic regimens for patients with conversion of the receptor status from primary to metastatic lesions have always been of concern for clinicians, particularly since the guidelines have not been clearly defined $[18,19]$.
In this study, we aimed to evaluate the frequency and prognostic value of receptor conversion between primary and first metastatic lesions in 411 patients at the first time of metastatic breast cancer recurrence. We also clarified the impact of receptor conversion on the choice of treatment and adapted treatment based on the reevaluation of metastatic lesions. This has shown significant improvements in the prognosis of patients with metastatic breast cancer. Our study has provided evidence for precision treatment according to the receptor status during the reevaluation of metastatic lesions of breast cancer. 
Table 2. Conversion of ER, PR, and HER2 $(n=411)$

\begin{tabular}{|c|c|c|c|c|c|}
\hline Primary site & $n$ & $\%$ & Metastasis site & $n$ & $\%$ \\
\hline $\mathrm{ER}+$ & 242 & 58.88 & $\begin{array}{l}\text { ER+ } \\
\text { ER- }\end{array}$ & $\begin{array}{r}194 \\
48\end{array}$ & $\begin{array}{l}80.17 \\
19.83\end{array}$ \\
\hline ER- & 169 & 41.12 & $\begin{array}{l}\text { ER+ } \\
\text { ER- }\end{array}$ & $\begin{array}{r}49 \\
120\end{array}$ & $\begin{array}{l}28.99 \\
71.01\end{array}$ \\
\hline $\mathrm{PR}+$ & 228 & 55.47 & $\begin{array}{l}\mathrm{PR}+ \\
\mathrm{PR}-\end{array}$ & $\begin{array}{r}153 \\
75\end{array}$ & $\begin{array}{l}67.11 \\
32.89\end{array}$ \\
\hline PR- & 183 & 44.53 & $\begin{array}{l}\mathrm{PR}+ \\
\mathrm{PR}-\end{array}$ & $\begin{array}{r}45 \\
138\end{array}$ & $\begin{array}{l}24.59 \\
75.41\end{array}$ \\
\hline HER2+ & 96 & 23.36 & $\begin{array}{l}\text { HER2+ } \\
\text { IHC without FISH } \\
\text { HER2- } \\
\text { NA }\end{array}$ & $\begin{array}{r}45 \\
35 \\
13 \\
3\end{array}$ & $\begin{array}{r}47.37 \\
36.84 \\
13.68 \\
3.16\end{array}$ \\
\hline HER2- & 270 & 65.69 & $\begin{array}{l}\text { HER2+ } \\
\text { IHC without FISH } \\
\text { HER2- } \\
\text { NA }\end{array}$ & $\begin{array}{r}18 \\
63 \\
172 \\
17\end{array}$ & $\begin{array}{r}6.82 \\
23.86 \\
65.15 \\
6.44\end{array}$ \\
\hline
\end{tabular}

NA, not available.

\section{Materials and Methods}

\section{Patients}

We collected the data of 635 patients with advanced breast cancer from the Department of Oncology, the First Affiliated Hospital of China Medical University, between January 2001 and September 2019. All the patients had previously undergone radical resection of the primary lesion and repeat pathological biopsy of the first metastatic lesion. The exclusion criteria were as follows: (1) patients with missing immunohistochemical results of ER and PR status in both primary and metastatic lesions and (2) patients who were lost to follow-up; 411 patients were finally included. This study was approved by the Ethics Committee of the First Hospital of China Medical University. We obtained informed consent from every patient.

Repeat biopsy of metastatic lesions includes pathological examination after puncture and pathological examination after surgical resection. The immunohistochemical results of ER, PR, and HER2 status were from 2 independent pathology experts. Expression of ER and PR $\geq 10 \%$ was considered to be positive for primary and metastatic lesions, respectively. HER2 status was defined as negative when the immunohistochemical result of HER2 was - or $1+$ and as positive when the immunohistochemistry result was $3+$. When the immunohistochemistry result of HER2 is $2+$, it is recommended that patients should be tested for HER2 fluorescence in situ hybridization (FISH) to make a final determination of HER2 status.

The last follow-up date of all patients was October 2019. Six patients (1.44\%) were lost to follow-up.

\section{Statistical Analysis}

Post-recurrence survival is defined as the time a patient was first pathologically diagnosed with metastatic breast cancer to the patient's death or her last follow-up visit (October 2019). KaplanMeier analysis was used to obtain survival curves. The log-rank test was applied to calculate statistical significance ( $p$ value). Differ- ences in the conversion among different metastatic sites were calculated using the $\chi^{2}$ test. $p<0.05$ is considered to be statistically significant. All statistical tests were performed on SPSS 24.0 software.

\section{Results}

\section{Clinical Characteristics of the Patients with Primary}

\section{Breast Cancer}

This study included 411 female patients diagnosed with metastatic breast cancer at the first time of recurrence. Their basic clinicopathological characteristics are summarized in Table 1. The median follow-up time after recurrence was 57.2 months. In $26.76 \%$ of the patients, metastases were confirmed pathologically by surgical resection while $73.24 \%$ were identified by puncture. According to the ER and PR status of the 411 patients with primary tumors, 242 (58.88\%) were ER+ and 228 (55.47\%) were $\mathrm{PR}+$. At the time of the initial diagnosis of breast cancer, $80 \%$ of patients were between 35 and 60 years of age, a ratio that was relatively equivalent between the ER+ or ER- and PR+ or PR-subgroups; $66 \%$ of women were menopausal. More than $50 \%$ of patients were in T2 stage, and the proportion of patients in N0 stage was relatively high. Nearly $50 \%$ of patients were of grade II; $8 \%$ of patients had a HER2 immunohistochemical result of $2+$, but no further HER2-FISH testing was performed due to patient reasons. 
(A)

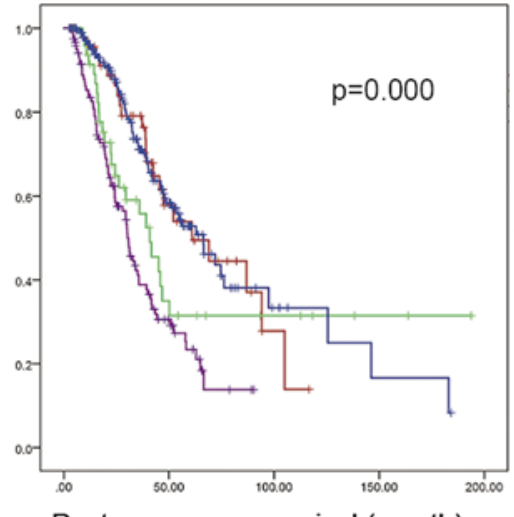

Post-recurrence survival (month)

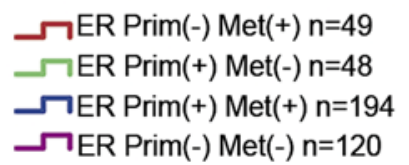

(B)

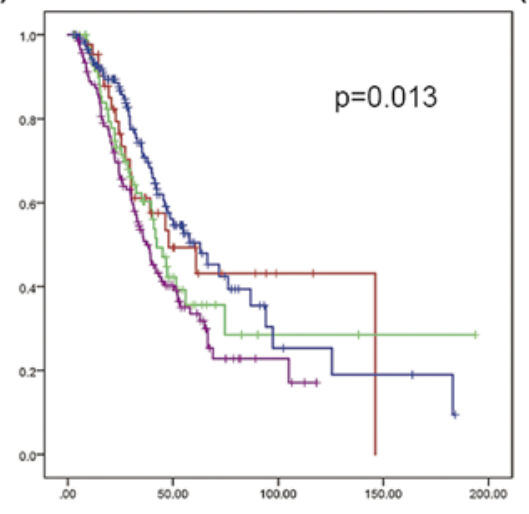

Post-recurrence survival (month)

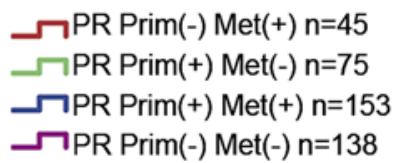

(C)

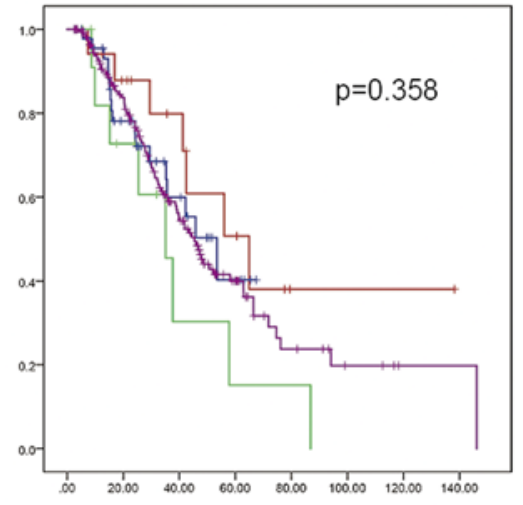

Post-recurrence survival (month)

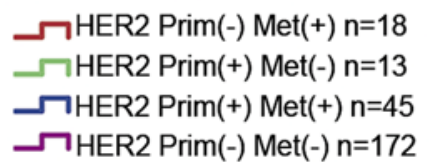

Fig. 1. Kaplan-Meier survival curves in patients with various ER status subtypes (A), patients with various $P R$ status subtypes (B), and patients with various HER2 status subtypes (C).

Table 3. Sites of re-biopsy and proportion of receptor conversion at each site

\begin{tabular}{|c|c|c|c|c|c|c|c|c|c|c|c|c|}
\hline \multirow[t]{2}{*}{ Site } & \multicolumn{2}{|c|}{ Total } & \multicolumn{2}{|c|}{ ER: Prim-Met+ } & \multicolumn{2}{|c|}{ ER: Prim+ Met $(-)$} & \multicolumn{3}{|c|}{ PR: Prim-Met+ } & \multicolumn{3}{|c|}{ PR: Prim+ Met- } \\
\hline & $n$ & $\%$ & $n$ & $\%$ & $n$ & $\%$ & $n$ & $\%$ & $p$ value & $n$ & $\%$ & $p$ value \\
\hline Total & 411 & 100.00 & 49 & $11.92^{\mathrm{a}}$ & 48 & $11.68^{\mathrm{b}}$ & 213 & 51.82 & 0.087 & 75 & 18.25 & 0.067 \\
\hline Brain & 7 & 1.70 & 1 & 14.29 & 1 & 14.29 & 0 & 0.00 & 1.000 & 3 & 42.86 & 0.228 \\
\hline Liver and lung & 78 & 18.98 & 9 & 11.54 & 9 & 11.54 & 5 & 6.41 & 0.154 & 17 & 21.79 & 0.368 \\
\hline Other internal organs & 44 & 10.71 & 5 & 11.36 & 9 & 20.45 & 3 & 6.82 & 0.501 & 8 & 18.18 & 0.990 \\
\hline Bone & 27 & 6.57 & 6 & 22.22 & 4 & 14.81 & 5 & 18.52 & 0.325 & 9 & 33.33 & 0.066 \\
\hline Opposite breast & 23 & 5.60 & 3 & 13.04 & 3 & 13.04 & 0 & 0.00 & 0.165 & 5 & 21.74 & 0.866 \\
\hline
\end{tabular}

${ }^{\mathrm{a}} \mathrm{p}=0.683,{ }^{\mathrm{b}} \mathrm{p}=0.451$.

Receptor Conversion between Primary Tumor and Metastatic Diseases

The frequency of receptor conversion is shown in Table 2. Among the 242 patients with ER+ primary lesions, $48(19.38 \%)$ patients with ER+ primary lesions changed to ER- metastatic lesions, and among 169 patients with ER-primary lesions, 49 (28.99\%) patients were ER+ in metastatic lesions. Similarly, the PR status of 75 (32.89\%) of 228 patients changed from positive to negative, while $45(24.59 \%)$ of the 183 patients converted from negative to positive. With the exception of patients without clarified HER2 status, $13.68 \%$ changed from primary HER2+ to metastatic HER2-, and 6.44\% from primary HER2- to metastatic HER2+.
According to the status conversion of ER, PR, and HER2 between primary and first metastatic lesions, patients were divided into 4 subgroups: Prim-Met+, Prim+ Met-, Prim+ Met+, and Prim-Met-. There were significant differences in post-recurrence survival (ER: $p=$ 0.000 , PR: $p=0.013$ ) in the ER and PR groups (Fig. 1a, b), but there was no statistical difference in the HER2 group (Fig. 1c, $p=0.358$ ).

\section{Site of Re-Biopsy and Proportion of Receptor}

Conversion at Each Site

The recurrence and metastasis re-biopsy site varied from patient to patient (Table 3); in $56.45 \%$ of patients, the re-biopsy sites were lymph nodes, soft tissue, or skin. 


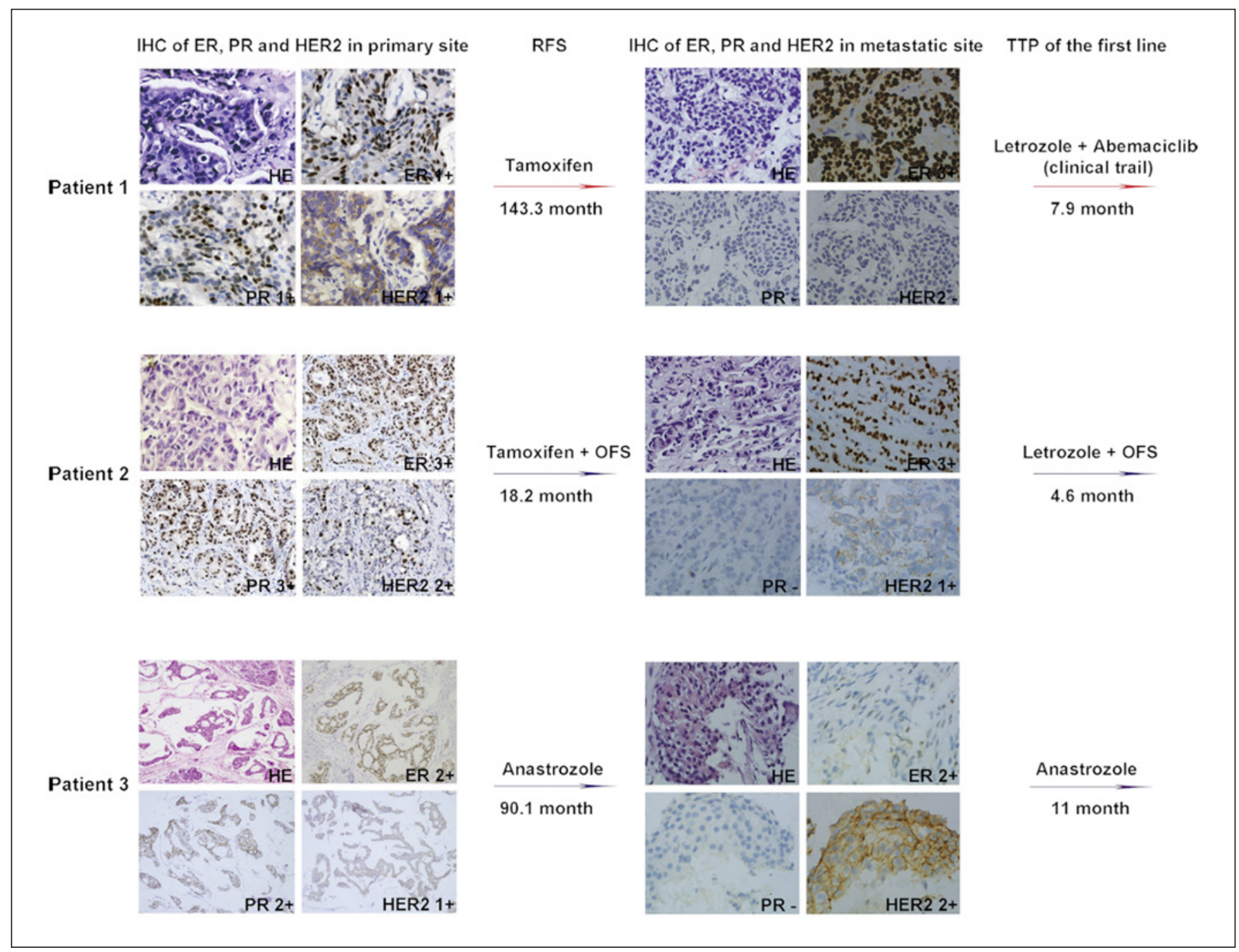

Fig. 2. Immunohistochemistry results of 3 patients with $E R+/ P R+$ primary and metastatic lesions and $P R-$ metastatic lesions. Adjuvant therapy regimens, first-line therapy regimens, recurrence-free survival (RFS) and timeto progression (TTP) were listed. OFS, ovarian function suppression.

Other internal organs include distant lymph nodes, chest, and abdominal organs except for the liver and lung. In all patients, both the proportions of ER from positive to negative and negative to positive were about $12 \%$, whereas the proportion of $\mathrm{PR}$ from negative to positive was $10.95 \%$, and the proportion of PR from negative to positive was $18.25 \%$.

For the PR Prim+ Met- and Prim-Met+ groups, no statistical differences were observed $(p=0.087, p=0.067)$ in receptor conversion at metastatic sites. Therefore, in these 2 groups, the conversion of the receptors at the target site were compared with the conversion of the receptors at all remaining re-biopsy sites. The $\chi^{2}$ test was used to confirm that there were significant differences in the PR status conversion in lymph nodes, soft tissue, or skin compared with the other sites in the PR Prim+ Met- subgroup $(p=0.016)$ and the PR Prim-Met+ subgroup ( $p=$ 0.036). For the PR Prim+ Met- subgroup, the PR status conversion of bone metastasis sites tended to be different from other sites $(p=0.066)$.

There are 9 patients in the PR Prim+ Met- subgroup with bone re-biopsied, and 3 of them caught our attention. The ER status of primary and metastatic lesions of these 3 patients was positive $(2+$ or $3+)$, and thus they accepted endocrine therapy as first-line regimens (Fig. 2). All of them obtained benefits from adjuvant endocrine therapy as their recurrence-free survival was 18.2, 90.1, and 143.3 months, respectively. However, all of the 3 patients were resistant to the endocrine therapy because time to progression from first-line treatment was $<1$ year.

Influence of Receptor Conversion after Re-Biopsy on First-Line Treatment

Endocrine therapy and HER2-targeted therapy are very important treatments currently in use. We have 
Table 4. Treatment after re-biopsy

\begin{tabular}{lc}
\hline Variable & $n(\%)$ \\
\hline First-line regimens of ER and/or PR Prim- Met+ & 77 \\
Chemotherapy & $29(37.66)$ \\
Endocrine therapy and/or chemotherapy & $36(46.75)$ \\
HER2-tageted therapy & $11(14.29)$ \\
No treatment & $1(1.30)$ \\
Multiline regimens of HER2 Prim- Met+ & 18 \\
Chemotherapy & $2(11.76)$ \\
Endocrine therapy and/or chemotherapy & $4(23.53)$ \\
HER2-tageted therapy & $12(70.59)$ \\
\hline
\end{tabular}

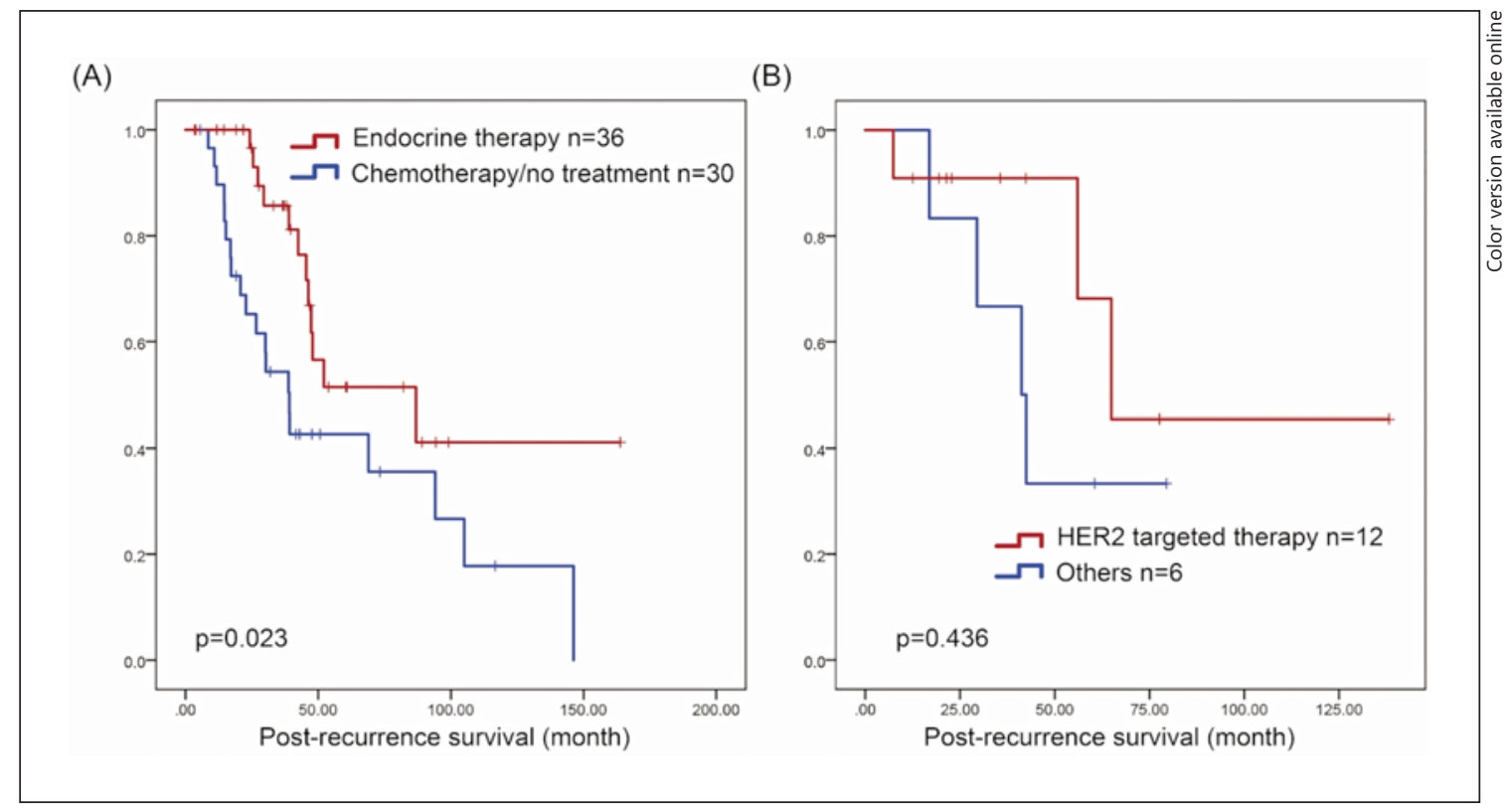

Fig. 3. Kaplan-Meier survival curves in patients in ER or PR Prim- Met+ subgroups received different first-line regimens $(\mathbf{A})$ and patients in HER2 Prim-Met+ subgroup with or without HER2 targeted therapy in multiline treatment $(\mathbf{B})$.

observed the first-line treatment options in the ER or PR Prim-Met+ subgroups and multiline treatment options in the HER2 Prim-Met+ subgroup (Table 4). Of the 77 patients in the ER or PR Prim- Met+ subgroup, $36(46.75 \%)$ were subjected to endocrine therapy with or without chemotherapy as first-line treatment regimen, and 29 (37.66\%) had chemotherapy alone. In order to rule out the effects of HER2-targeted therapy, we excluded 11 patients on HER2-targeted therapy containing herceptin. Patients on endocrine therapy had a significantly better prognosis than patients on chemotherapy alone (Fig. 3a; $p=0.029$ ). Also, we analyzed the impact of targeted therapy on prognosis in the HER2 Prim-Met+ subgroup and concluded that the prognosis of 12 patients on HER2-targeted therapy in multiline treatment tended to be better than that of 6 patients on chemotherapy or endocrine therapy only (Fig. 3b; $p=$ 0.436).

\section{Discussion}

In this study, comparing the status of ER, PR, and HER2 between primary and first metastatic lesions in 411 patients with metastatic breast cancer treated in a single center, it was found that the receptor status did undergo a conversion, to a certain extent, between primary and metastatic sites. Patients had a significantly better prognosis when ER or PR status changed from negative to positive in univariant analysis. However, the post-recurrence survival of patients treated with endocrine therapy as first-line regimen was significantly better than that of patients treated with chemotherapy alone when ER or PR changed from negative to positive. All the results indicate that re-biopsy of the metastatic site to detect the receptor status is important to be able to tailor treatment to the individual patient with metastatic breast cancer. 
An increasing number of guidelines recommends a rebiopsy of metastatic breast cancer to determine the receptor status and molecular subtype [17-19]. Several previous studies have found that the rates of receptor status conversion were different, but due to small sample sizes, the ratios of negative to positive and positive to negative have not been separately calculated. In a systematic review and meta-analysis, Schrijver et al. [16] found that the rates of receptor conversion differed among different metastatic sites. In our study, the rates of ER and PR receptor status conversion were calculated in detail using a large number of patients accrued in a single center. The rate of PR status conversion in lymph nodes, soft tissue, or skin is significantly different from other sites suggesting that, in future clinical work, these patients should be subjected to a re-biopsy to determine outcome and future therapy based on the receptor status. Interestingly, the proportion of receptor conversion after re-biopsy of bone metastases was different compared with other sites in the PR Prim+ Met- subgroup, which has great implications for future clinical work to establish the applications of endocrine therapy. Thus, patients with bone metastases should undergo a distinctive therapeutic approach as they should perform re-biopsy of metastases actively.

Usually, endocrine therapy is the first choice for hormone receptor-positive metastatic breast cancer without visceral crisis, although previous studies have shown that when endocrine resistance develops, nearly half of the patients have PR loss, and PR-status can guide the prediction of resistance [20-23]. When PR changes from positive to negative, perhaps resistance to endocrine therapy should be considered. In this study, there were 3 special patients with $\mathrm{ER}+/ \mathrm{PR}+$ primary lesions who benefited from the adjuvant endocrine therapy, but the PR status changed to negative after re-biopsy at the first time of bone recurrence. They were primarily resistant to first-line endocrine therapy because of relatively short interval from first-line therapy to progression. We could not draw the conclusion that metastatic breast cancer patients with a PR change from positive to negative at the bone recurrence site are resistant to first-line endocrine therapy due to the limited number of patients, but the therapy regimens of metastatic breast cancer patients with bone recurrence and $\mathrm{PR}$ conversion are worthy further investigation. Whether the PR conversion from positive to negative at bone metastatic site can be a biomarker of endocrine therapy resistance needs to be addressed in future clinical work.

Previous studies and this article have shown that receptor conversion is an important factor in predicting the prognosis of patients with metastases $[8,9,11,24]$. In fact, the clinicians' priority is to know if the receptor conversion can influence their clinical decisions and therefore patient outcome. At present, conclusive data on receptor conversion in metastatic lesions still lack, and there are no clear guidelines providing information about treatment regimens and receptor status in metastatic lesions. Therefore, to the best of our knowledge, for the first time, we retrospectively explored the effect of receptor conversion on the decision of first- or multiline regimens and on the prognosis of patients with metastatic breast cancer. Nearly half of the patients were on regimens containing endocrine therapy as the first-line treatment according to the receptor status of metastatic sites, when ER or PR change from negative to positive. The post-recurrence survival was significantly better than that based on the primary receptor status applying chemotherapy only. However, there was no statistically significant better prognosis in patients in the HER2 Prim-Met+ subgroup who received HER2-targeted therapy in multiline treatment, which may be due to the small sample size. Consequently, in clinical practice, clinicians should provide patients with an individualized treatment plan based on the patient's own situation combined with receptor conversion information at metastatic sites.

Our study also has some limitations. First, as a retrospective study, patients included in this study are admitted to a single center, and there will be some bias. The sample size in some subgroups is small and multicentric. Thus, a prospective study in a large patient cohort is needed to confirm the results. Second, due to some patientrelated factors, the proportion of ambiguous HER2 status is high. This also requires larger sample data to further clarify the impact of HER2 conversion on patient prognosis. Finally, due to limitations of the re-biopsy methods, patients with multiple metastases generally choose only 1 metastasis for re-biopsy, which may also have some impact on the results.

\section{Conclusion}

In the 411 patients with pathologically diagnosed metastatic breast cancer at the first time of recurrence studied in a single center, ER and PR conversions were found to affect the prognosis of patients and decisions regarding the treatment regimen. Patients may benefit from therapy regimens based on the receptor status of metastatic lesions. It is clear that the receptor status at metastatic sites and receptor conversion between the primary and metastatic lesions have important effects on tailored treatment of metastatic breast cancer, which may significantly improve the prognosis of patients with metastatic breast cancer.

\section{Statement of Ethics}

This study was approved by the Ethics Committee of the First Hospital of China Medical University. We obtained informed consent from every patient.
Shen/Xu/Shi/Zhao/Shi/Feng/Han/Shi/ Wei/Wang/Sun/Mi/Teng 


\section{Conflict of Interest Statement}

All authors declare that there are no potential conflicts of interest including any financial, personal, or other relationships with other people or organizations that could inappropriately influence this work.

\section{Funding Sources}

This work was supported by the National Natural Science Foundation of China (NSFC, No. 81672605), National Key R\&D Program of China (No. 2018YFC1311600), and the Science and Technology Plan Project of Liaoning Province (No. 2016007010).

\section{Author Contributions}

All authors contributed to the study. The study was designed by Yue'e Teng. Material preparation and data collection were performed by Jiming Shen, Lu Xu, Jing Shi, Lei Zhao, Sha Shi, Jing Feng, Xu Han, Yu Shi, Qiaochu Wei, Dongni Wang, Mingfang Sun, and Xiaoyi Mi. Analyses were performed by Jiming Shen and $\mathrm{Lu} \mathrm{Xu}$. The first draft of the manuscript was written by Jiming Shen, and reviewed and edited by Yue'e Teng and Lu Xu. All authors read and approved the final manuscript.

\section{References}

1 DeSantis C, Ma J, Bryan L, Jemal A. Breast cancer statistics, 2013. CA Cancer J Clin. 2014 Jan-Feb;64(1):52-62.

2 Bray F, Ferlay J, Soerjomataram I, Siegel RL, Torre LA, Jemal A. Global cancer statistics 2018: GLOBOCAN estimates of incidence and mortality worldwide for 36 cancers in 185 countries. CA Cancer J Clin. 2018 Nov;68(6): 394-424.

3 Nicolini A, Ferrari P, Duffy MJ. Prognostic and predictive biomarkers in breast cancer: past, present and future. Semin Cancer Biol. 2018 Oct;52(Pt 1):56-73.

4 AG W. JAMA WEJ. Breast. Cancer Treat Rev. 2019;321(3):288-300.

5 McCart Reed AE, Kalita-De Croft P, Kutasovic JR, Saunus JM, Lakhani SR. Recent advances in breast cancer research impacting clinical diagnostic practice. J Pathol. 2019 Apr;247(5):552-62.

6 Harbeck N, Penault-Llorca F, Cortes J, Gnant M, Houssami N, Poortmans P, et al. Breast Cancer. 2019;5(1):66.

7 Hoefnagel LD, van de Vijver MJ, van Slooten HJ, Wesseling P, Wesseling J, Westenend PJ, et al. Receptor conversion in distant breast cancer metastases. Breast Cancer Res. 2010; 12(5):R75.

8 Hoefnagel LD, Moelans CB, Meijer SL, van Slooten HJ, Wesseling P, Wesseling J, et al. Prognostic value of estrogen receptor $\alpha$ and progesterone receptor conversion in distant breast cancer metastases. Cancer. 2012 Oct 118(20):4929-35.

9 Lindström LS, Karlsson E, Wilking UM, Johansson U, Hartman J, Lidbrink EK, et al. Clinically used breast cancer markers such as estrogen receptor, progesterone receptor, and human epidermal growth factor receptor 2 are unstable throughout tumor progression. J Clin Oncol. 2012 Jul;30(21):2601-8.
10 Krøigård $\mathrm{AB}$, Larsen $\mathrm{MJ}$, Thomassen $\mathrm{M}$, Kruse TA. Molecular concordance between primary breast cancer and matched metastases. Breast J. 2016 Jul;22(4):420-30.

11 Meng X, Song S, Jiang ZF, Sun B, Wang T, Zhang S, et al. Receptor conversion in metastatic breast cancer: a prognosticator of survival. Oncotarget. 2016 Nov;7(44):71887903.

12 Fujii K, Watanabe R, Ando T, Kousaka J, Mouri Y, Yoshida M, et al. Alterations in three biomarkers (estrogen receptor, progesterone receptor and human epidermal growth factor 2 ) and the Ki67 index between primary and metastatic breast cancer lesions. Biomed Rep. 2017 Dec;7(6):535-42.

13 Altundag K. Receptor conversion in breast cancer patients with liver metastases after hepatectomy might affect survival. Breast Cancer Res Treat. 2018 Jul;170(2):441.

14 Altundag K. Receptor conversion in breast cancer brain metastases may affect survival. Clin Neurol Neurosurg. 2018 Aug;171:194.

15 Jung J, Lee SH, Park M, Youn JH, Shin SH, Gwak HS, et al. Discordances in ER, PR, and HER2 between primary breast cancer and brain metastasis. J Neurooncol. 2018 Apr; 137(2):295-302.

16 Schrijver WA, Suijkerbuijk KP, van Gils $\mathrm{CH}$, van der Wall E, Moelans CB, van Diest PJ. Receptor conversion in distant breast cancer metastases: a systematic review and metaanalysis. J Natl Cancer Inst. 2018 Jun;110(6): 568-80.

17 Van Poznak C, Somerfield MR, Bast RC, Cristofanilli M, Goetz MP, Gonzalez-Angulo AM, et al. Use of biomarkers to guide decisions on systemic therapy for women with metastatic breast cancer: American Society of Clinical Oncology Clinical Practice Guideline. J Clin Oncol. 2015 Aug;33(24):2695-704.
18 Cardoso F, Costa A, Norton L, Cameron D, Cufer T, Fallowfield L, et al. 1st International consensus guidelines for advanced breast cancer (ABC 1). Breast. 2012 Jun;21(3):24252.

19 Carlson RW, Allred DC, Anderson BO, Burstein HJ, Edge SB, Farrar WB, et al; National Comprehensive Cancer Network. Metastatic breast cancer, version 1.2012: featured updates to the NCCN guidelines. J Natl Compr Canc Netw. 2012 Jul;10(7):821-9.

20 Branković-Magić M, Janković R, NeskovićKonstantinović Z, Nikolić-Vukosavljević D. Progesterone receptor status of breast cancer metastases. J Cancer Res Clin Oncol. 2002 Jan; 128(1):55-60.

21 Cui X, Schiff R, Arpino G, Osborne CK, Lee $\mathrm{AV}$. Biology of progesterone receptor loss in breast cancer and its implications for endocrine therapy. J Clin Oncol. 2005 Oct;23(30): 7721-35.

22 Bartlett JM, Brookes CL, Robson T, van de Velde CJ, Billingham LJ, Campbell FM, et al. Estrogen receptor and progesterone receptor as predictive biomarkers of response to endocrine therapy: a prospectively powered pathology study in the Tamoxifen and Exemestane Adjuvant Multinational trial. J Clin Oncol. 2011 Apr;29(12):1531-8.

23 Bado I, Gugala Z, Fuqua SA, Zhang XH. Estrogen receptors in breast and bone: from virtue of remodeling to vileness of metastasis. Oncogene. 2017 Aug;36(32):4527-37.

24 Duchnowska R, Dziadziuszko R, Trojanowski T, Mandat T, Och W, Czartoryska-Arłukowicz $\mathrm{B}$, et al; Polish Brain Metastasis Consortium. Conversion of epidermal growth factor receptor 2 and hormone receptor expression in breast cancer metastases to the brain. Breast Cancer Res. 2012 Aug;14(4):R119. 